\title{
Aplicações de fibras vegetais na secagem de concretos refratários
}

\section{(Use of natural fibers to speed up the drying step of refractory castables)}

\author{
C. S. Isaac, R. Salomão, V. C. Pandolfelli \\ Departamento de Engenharia de Materiais - DEMa \\ Universidade Federal de S. Carlos \\ Rod. Washington Luiz, km 235, C.P. 676, S. Carlos, SP, 13565-905 \\ claudiasi@polvo.ufscar.br, \\ pers@iris.ufscar.br,vicpando@power.ufscar.br
}

\begin{abstract}
Resumo
A secagem de concretos refratários é uma etapa crítica em seu processamento devido aos riscos de explosão durante a saída de água contida em sua estrutura. Para minimizar esses problemas e aumentar a velocidade de secagem, fibras poliméricas têm sido adicionadas às formulações de concreto. Uma variável importante a ser considerada no desempenho desse aditivo é o tipo de fibra utilizada. Trabalhos do grupo de pesquisa indicaram que fibras vegetais podem apresentar bom desempenho na geração de canais permeáveis. Esse fato, aliado à sua grande disponibilidade e baixo custo, sugere que estas fibras sejam uma alternativa interessante às fibras sintéticas utilizadas atualmente. Neste trabalho, comparou-se o desempenho de fibras vegetais com o do polipropileno utilizados como aditivos de secagem. Foram realizadas medidas de permeabilidade utilizando a Equação de Forchheimer, ensaios de permeametria em alta temperatura e análise termogravimétrica do concreto. As fibras foram caracterizadas por calorimetria exploratória diferencial e termogravimetria.
\end{abstract}

Palavras-chave: concretos refratários, secagem, fibras vegetais.

\begin{abstract}
The drying of refractory castables is a critical step during application due to the possibility of spalling. In order to decrease these risks and improve the drying rate, polymeric fibers have been added to the castables'formulation. The type of fiber is an important aspect to be studied. Authors' previous works indicated that vegetable fibers can be good candidates. This fact, associated with its wide availability and low cost, suggests that these fibers can be interesting substitutes to synthetic ones. In this work, vegetable and polypropylene fibers had their performance evaluated as drying agents. The results of permeability measurements and hot air permeametry were related with the thermogravimety of the fiber-containing castables. The fibers were characterized by differential scanning calorimetry and thermogravimetry.
\end{abstract}

Keywords: refractory castables, drying, permeability, vegetable fibers.

\section{INTRODUÇÃO}

A secagem é uma etapa crítica do processamento de concretos refratários devido aos riscos de explosão durante a saída de água contida em sua estrutura. A baixa permeabilidade desses materiais dificulta a saída do vapor para o ambiente, podendo gerar trincas e explosões. Assim, a utilização de programas de secagem agressivos pode prejudicar a qualidade final do produto. Por outro lado, um programa de secagem muito lento pode não ser economicamente viável [1].

Entre as soluções atualmente utilizadas, a adição de fibras poliméricas às formulações de concretos refratários tem mostrado bons resultados [2, 3]. Após sua fusão e degradação formam-se canais que aumentam a permeabilidade do concreto, facilitando a saída do vapor de água [4, 6]. Embora as fibras de polipropileno (PP) sejam tradicionalmente utilizadas nessa aplicação desde os anos 80 , trabalhos recentes do grupo de pesquisa dos autores demonstraram que fibras vegetais podem apresentar um desempenho equivalente ao das fibras de polipropileno no aumento de permeabilidade [5, 6], além de sua grande disponibilidade e baixo custo. Isto sugere que as fibras vegetais possam ser uma alternativa interessante como aditivo de secagem.

Vegetal 1 é o nome dado, neste trabalho, à fibra extraída do caule de uma planta da família das Tiláceas. Estas fibras são muito longas e rígidas, e deterioram-se facilmente quando expostas à umidade [7]. Em cada planta, os feixes de células formam uma malha tubular que reveste o caule do início ao fim. Cada célula (ou fibrila) tem a forma poligonal, com um canal central contendo cerca de $10 \%$ da área transversal da célula [8]. Uma representação esquemática dessa estrutura é mostrada na Fig. 1. Esse tipo de fibra é muito utilizado na indústria têxtil e em compósitos. Já as fibras curtas são utilizadas na indústria de papel. 


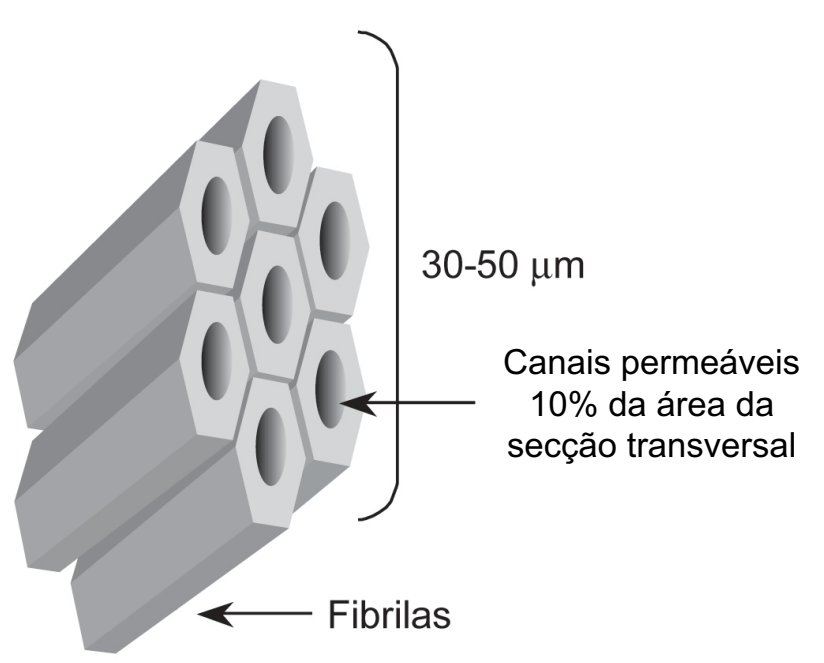

Figura 1: Representação esquemática da estrutura da fibra vegetal 1 [8]. [Figure 1: Schematic drawing of the morphology of vegetable fiber 1.]

A fibra Vegetal 2 é uma planta ornamental da família das Agaváceas [9]. Suas folhas são pontiagudas e grandes. A fibra, obtida através de separação manual ou raspagem, é rígida e de cor amarela-pálida. É uma planta originária do México e América Central, atualmente cultivada no Hawai, regiões da África e nordeste brasileiro. Sua estrutura é similar a da Vegetal 1 com um canal central em cada célula [8].

Neste trabalho, os desempenhos de fibras sintéticas (PP) e vegetais como aditivo de secagem foram comparados. Técnicas de medida e avaliação de permeabilidade foram utilizadas para verificar o mecanismo de atuação de cada tipo de fibra. O comportamento de secagem de concretos refratários contendo estas fibras foi comparado com aquele sem fibras (referência) por meio de termogravimetria.

\section{MATERIAIS E MÉTODOS}

Foi utilizada uma formulação de concreto auto-escoante desenvolvida através do modelo de distribuição de partículas de Andreasen (com coeficiente $\mathrm{q}=0,21$ ), calculada por meio do programa PS Designer, desenvolvido pelo grupo de pesquisa dos autores [10]. Composta por uma mistura de matriz fina $\left(24 \%\right.$ em peso, $\left.d_{p}<100 \mu \mathrm{m}\right)$ de agregados $(76 \%$ em peso, $\left.\mathrm{d}_{\mathrm{p}} \max =4,5 \mathrm{~mm}\right)$, a composição contém um total de $98 \%$ em peso de alumina e $2 \%$ em peso de cimento de aluminato de cálcio (CA 14, Alcoa EUA). O teor de água utilizado foi de $4,12 \%$ em peso ( $15 \%$ em vol.), sendo adicionado gradativamente em duas partes: a primeira com $77 \%$ em peso e a segunda com $23 \%$ em peso do total, ambas em uma taxa de $8 \mathrm{~g} / \mathrm{s}$.

As fibras vegetais e de polipropileno com $6 \mathrm{~mm}$ de comprimento $(0,36 \%$ em volume $)$ foram adicionadas à formulação de concreto refratário (Tabela I).

Depois de processadas em um misturador, as composições foram moldadas na forma de cilindros com $70 \mathrm{~mm}$ de diâmetro e $22 \mathrm{~mm}$ de espessura, para medidas de permeabilidade, e
Tabela I - Características típicas das fibras de polipropileno (PP), vegetal 1 e vegetal 2 .

[Table I - Typical characteristics of the tested fibers.]

\begin{tabular}{ccc}
\hline Fibras & Densidade $\left(\mathrm{g} / \mathrm{cm}^{3}\right)$ & Diâmetro $(\mu \mathrm{m})$ \\
\hline PP & 0,91 & 15 \\
\hline Vegetal 1 & 1,45 & $30-50$ \\
\hline Vegetal 2 & 1,40 & $40-100$ \\
\hline
\end{tabular}

com $40 \mathrm{~mm}$ de diâmetro e $40 \mathrm{~mm}$ de espessura, para os ensaios de secagem.

Amostras para medidas de permeabilidade foram curadas por 72 horas a $50{ }^{\circ} \mathrm{C}$ com umidade relativa de $\approx 100 \%$. A seguir, parte delas foi colocada em uma câmara climatizada (Vötsch 2002 ) a $50{ }^{\circ} \mathrm{C}$ com umidade relativa de $\approx 20 \%$, para serem utilizadas em ensaios de medida de permeabilidade a verde e após tratamento térmico a $900{ }^{\circ} \mathrm{C}$ por 6 horas. As amostras restantes foram mantidas úmidas para ensaios de permeametria de ar quente. Amostras para ensaio de secagem foram curadas por 72 horas a $8{ }^{\circ} \mathrm{C}$ em ambiente com umidade relativa de $\approx 100 \%$, sendo a seguir ensaiadas.

A caracterização das fibras foi feita por meio de calorimetria exploratória diferencial (CED, Netzsch DSC 204) e termogravimetria (TG, Netzsch TG 209), na faixa de temperatura entre $20{ }^{\circ} \mathrm{C}$ e $600{ }^{\circ} \mathrm{C}$, com taxa de $5{ }^{\circ} \mathrm{C} / \mathrm{min}$, em atmosfera oxidante (ar sintético).

As constantes de permeabilidade $\left(\mathrm{k}_{1}\right.$ e $\left.\mathrm{k}_{2}\right)$ foram obtidas por meio da equação de Fochheimer (Equação A) para escoamento de fluidos compressíveis [11]:

$$
\frac{\mathrm{P}_{\mathrm{i}}^{2}-\mathrm{P}_{0}^{2}}{2 \mathrm{P}_{0} \mathrm{~L}}=\frac{\mu}{\mathrm{k}_{1}} \mathrm{v}_{\mathrm{s}}+\frac{\rho}{\mathrm{k}_{2}} \mathrm{v}_{\mathrm{s}}^{2}
$$

onde, $\mathrm{P}_{\mathrm{i}}$ e $\mathrm{P}_{0}$ são as pressões absoluta do ar na entrada e na saída da amostra, respectivamente; L é a espessura da amostra; $\mathrm{v}_{\mathrm{s}}, \mu$ e $\rho$ são, respectivamente, a velocidade, a viscosidade e a densidade do fluido.

A técnica de permeametria de ar quente (PAT) [12] permite que mudanças estruturais do concreto sejam observadas na temperatura em que ocorrem, sem necessidade de tratamento térmico. Quando uma pressão constante é imposta para que o ar escoe através do meio poroso, a permeabilidade pode ser influenciada por diferentes fenômenos durante o processo de aquecimento. Se o experimento for realizado utilizando um gradiente de pressão elevado, o escoamento de ar através de poros permeáveis se torna muito sensível a rearranjos físicos e as variações de permeabilidade podem ser observadas [12]. Neste experimento, amostras úmidas foram aquecidas a $50{ }^{\circ} \mathrm{C}$ a uma taxa de aquecimento de $5{ }^{\circ} \mathrm{C} / \mathrm{min}$, permanecendo naquela temperatura por 10 horas. Nesse primeiro estágio de aquecimento é possível avaliar como a retirada de boa parte da água não combinada das amostras afeta a permeabilidade do concreto. A seguir, a temperatura foi reduzida até $25^{\circ} \mathrm{C}$ e em seguida elevada até $600^{\circ} \mathrm{C}$, na mesma taxa. Evidenciam- 
se, assim, mudanças de permeabilidade causadas por reações térmicas nas fibras e hidratos presentes [12].

Os ensaios de secagem e explosão foram realizados em um aparato desenvolvido pelo grupo de pesquisa dos autores. Tal equipamento permite registrar simultaneamente as variações de massa e os perfis de temperatura desenvolvidos entre a superfície e o centro das amostras durante o aquecimento [13]. Foi utilizada taxa de aquecimento igual a $10{ }^{\circ} \mathrm{C} / \mathrm{min}$, de $25^{\circ} \mathrm{C}$ a $800{ }^{\circ} \mathrm{C}$. As variações de massa foram acompanhadas por meio da derivada do parâmetro $\mathrm{W}$ em relação ao tempo, que avalia a fração cumulativa de massa perdida durante o aquecimento, em relação ao teor inicial de água na amostra (Equações B e C) [13]:

$$
\begin{aligned}
& W(\%)=100 \times \frac{M_{0}-M}{M_{0}-M_{f}} \\
& \left(\frac{d W}{d t}\right)_{i}=\frac{W_{i+1}-W_{i-1}}{t_{i+1}-t_{i-1}}
\end{aligned}
$$

onde $\mathrm{M}$ é a massa instantânea registrada no tempo $\mathrm{t}_{\mathrm{i}}$, durante o aquecimento; $\mathrm{M}_{0}$ é a massa inicial e $\mathrm{M}_{\mathrm{f}}$ a massa final da amostra.

\section{RESULTADOS E DISCUSSÃO}

Os resultados das medidas de permeabilidade em baixa temperatura $\left(\mathrm{k}_{2}\right)$, das amostras a verde e após tratamento térmico a $900{ }^{\circ} \mathrm{C}$, e do teor de cinzas das fibras após queima a $900{ }^{\circ} \mathrm{C}$ são mostrados na Fig. 2.
Nota-se que as amostras verdes e secas contendo fibras vegetais apresentaram valores de permeabilidade similares e significativamente superiores àqueles das amostras de referência e com fibras de PP $\left(\approx 10\right.$ vezes maior, para $\left.\mathrm{k}_{2}\right)$. Estes resultados indicam que, tanto a fibra vegetal 1 como a 2, podem gerar aumento de permeabilidade durante a secagem (em temperatura ambiente). Após a queima a $900{ }^{\circ} \mathrm{C}$, os três tipos de amostras com fibras tiveram aumentos de permeabilidade ainda maiores em relação à amostra de referência $(\approx 70$ vezes superior para o polipropileno, 20 vezes para a vegetal 1 e 15 vezes superior para a vegetal 2 , considerando $\mathrm{k}_{2}$ ).

Além disso, na Fig. 2 pode-se observar que as fibras de PP após calcinação não apresentam resíduos. As fibras vegetal 2 deixam uma quantidade de cinzas superior à gerada pela vegetal 1. Isso indica que, para níveis equivalentes de aumento de permeabilidade, a utilização das fibras vegetal 2 podem introduzir uma quantidade superior de fases de baixa refratariedade (principalmente $\mathrm{CaO}$ e $\mathrm{K}_{2} \mathrm{O}$ ), em relação às fibras vegetal 1 e polipropileno.

A Fig. 3 apresenta os resultados de permeametria de ar quente para o primeiro estágio de aquecimento (temperatura das amostras constante $\mathrm{e} \approx 55^{\circ} \mathrm{C}$, durante 10 horas) para amostras de concretos com fibras de PP, vegetal 1 e para amostra de referência.

Durante a secagem até $\approx 50^{\circ} \mathrm{C}$, as amostras sem fibras e com fibras de PP apresentaram perfis de vazão similares, atingindo valores próximos a $12 \mathrm{~mL} / \mathrm{min}$. Para a amostra contendo fibras vegetais, os aumentos de vazão foram mais rápidos e significativamente maiores $(\approx 4$ vezes, em relação ao nível atingido pelo concreto de referência). Pelos resultados, pode-se notar que a permeabilidade das amostras verdes com fibras vegetais é maior após a secagem a $50{ }^{\circ} \mathrm{C}$, e seu mecanismo de atuação é demonstrado na Fig. 4.

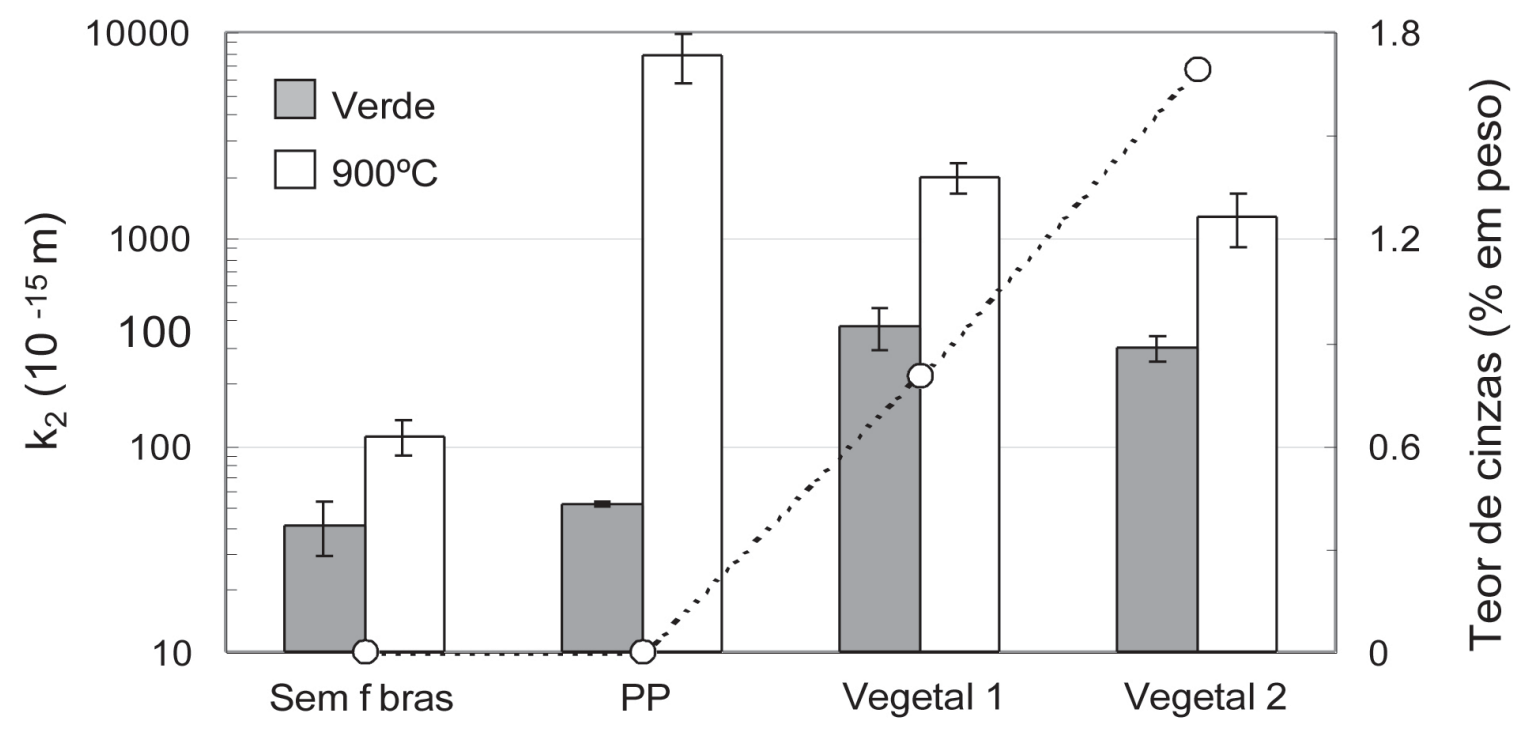

Figura 2: Medidas de permeabilidade $\left(\mathrm{k}_{2}\right)$ de amostras verdes e tratadas termicamente a $900{ }^{\circ} \mathrm{C}$ e do teor de cinzas $\left(900{ }^{\circ} \mathrm{C}\right)$ para os vários tipos de fibras.

[Figure 2: Permeability measurements $\left(k_{2}\right)$ : green and fired $\left(900{ }^{\circ} \mathrm{C}\right)$ samples and amount of ashes after burnout (900 $\left.{ }^{\circ} \mathrm{C}\right)$ for the several types of fibers employed.] 


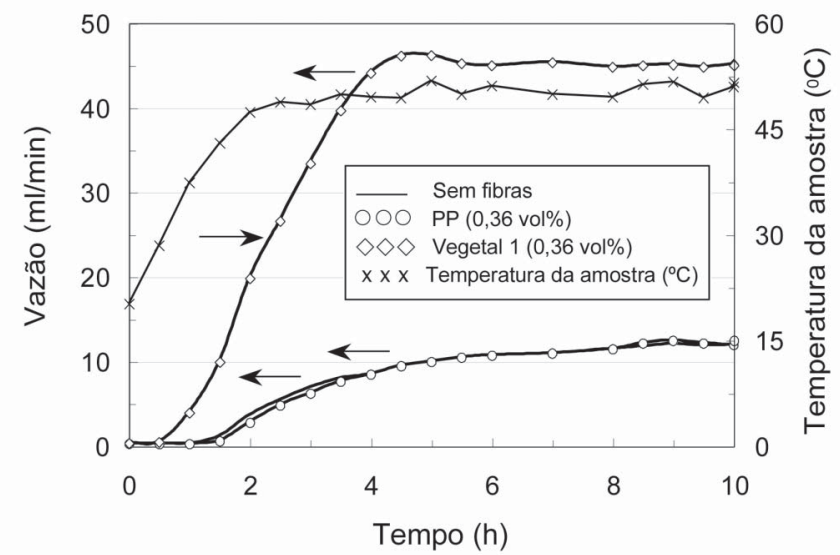

Figura 3: Resultados de permeametria de ar quente (primeiro estágio: $10 \mathrm{~h}$ a $50{ }^{\circ} \mathrm{C}$ ) para amostras de concreto contendo fibras de polipropileno e vegetal 1 e para a amostra de referência.

[Figure 3: Hot air permeametry results (first stage: 10 h at $50{ }^{\circ} \mathrm{C}$ ) for castables samples containing polypropylene and vegetable fibers and for reference sample.]

A fibra vegetal 1 seca após o corte da planta apresenta uma considerável diminuição na secção transversal (redução por volta de $25 \%$ no diâmetro), devido à contração das paredes da fibra. Uma vez adicionadas a um meio aquoso (como o concreto), essas fibras absorvem água e incham, recuperando seu diâmetro original [8]. Durante a cura do concreto, a solidificação preserva os canais gerados ao redor das fibras com diâmetro das fibras inchadas. Na secagem do concreto a $50^{\circ} \mathrm{C}$, as fibras encolhem novamente, diminuindo sua secção transversal. Este processo permite que novos canais permeáveis possam ser formados em faixas de temperatura próximas à ambiente.

As Figs. 5, 6 e 7 mostram os resultados de: a) permeametria de ar quente (segundo estágio de aquecimento: 25 a $600^{\circ} \mathrm{C}$, a
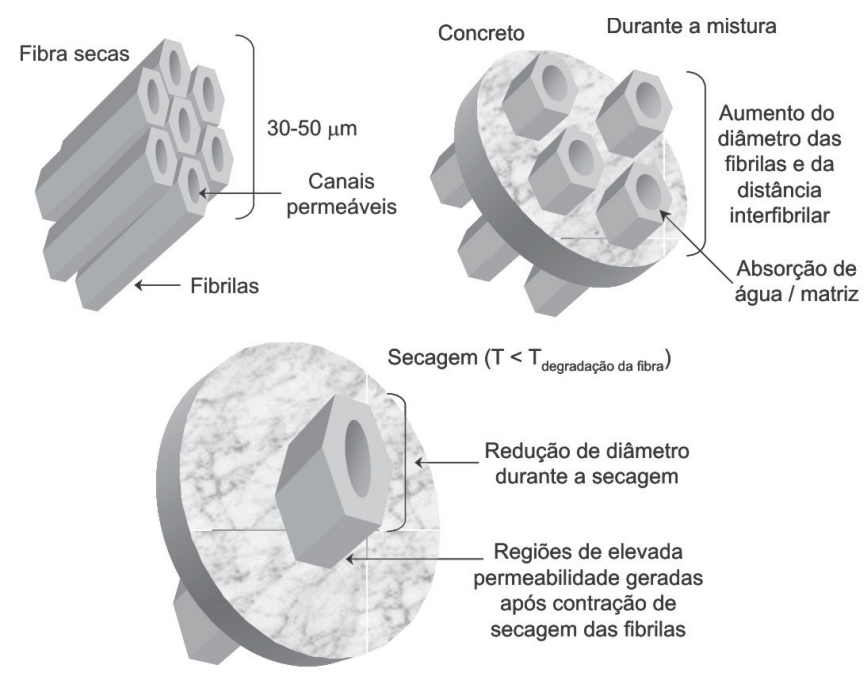

Figura 4: Mecanismo de aumento permeabilidade de concretos com fibras vegetal 1 e 2 em baixa temperatura $\left(50^{\circ} \mathrm{C}\right)$.

[Figure 4: Mechanism of permeability increase for vegetal 1 and vegetal 2 fiber-containing castables at low temperature $\left(50^{\circ} \mathrm{C}\right)$.]
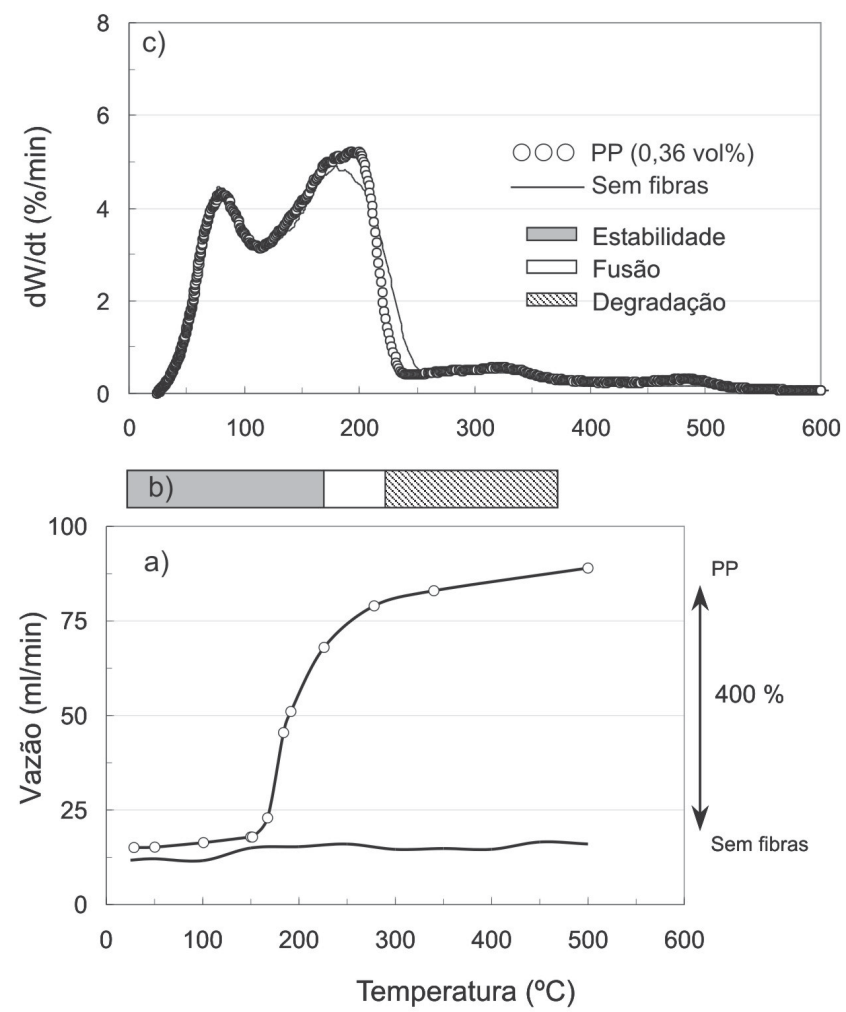

Figura 5: a) Permeametria de ar quente (segundo estágio de aquecimento: $50{ }^{\circ} \mathrm{C}$ a $600{ }^{\circ} \mathrm{C}$ ), b) Caracterização térmica das fibras e c) Comportamento de secagem a $10{ }^{\circ} \mathrm{C} / \mathrm{min}$ para amostras de concretos com fibras de polipropileno.

[Figure 5: a) Hot air permeametry (second stage: $50{ }^{\circ} \mathrm{C}$ to $600{ }^{\circ} \mathrm{C}$ ), b) Thermal characterization of polypropylene fiber and c) Drying behavior at $10{ }^{\circ} \mathrm{C} / \mathrm{min}$ for samples containing polypropylene fibers.]

$5{ }^{\circ} \mathrm{C} / \mathrm{min}$ ), b) representação das faixas de transformação térmica das fibras e c) comportamento de secagem a $10^{\circ} \mathrm{C} / \mathrm{min}$ para amostras de concretos com fibras de polipropileno, vegetal 1 e vegetal 2, respectivamente.

Os resultados de permeametria de ar quente (Figs. 5a, 6a e 7a) mostram que os níveis de vazão das amostras sem fibras, com fibras de PP e com fibras vegetais se mantiveram estáveis entre $25{ }^{\circ} \mathrm{C}$ e $120-150{ }^{\circ} \mathrm{C}$ (sendo que as fibras vegetais apresentam níveis iniciais de vazão significativamente superiores). Nessa mesma faixa de temperatura, não foram observadas reações térmicas nas fibras (Figs. 5b, 6b e 7b) nem diferenças no comportamento de secagem (Figs. 5c, 6c e 7c).

Entre 150 e $200{ }^{\circ} \mathrm{C}$, a vazão das amostras sem fibras e contendo fibras vegetais manteve-se estável, embora em níveis distintos (Figs, 5a, 6a e 7a). A amostra com fibras de PP, no entanto, apresentou um expressivo e localizado aumento de vazão $(\approx 4$ vezes em relação à mesma temperatura na amostra sem fibras). Esse fato está relacionado com o aumento de permeabilidade gerado pela fusão e degradação desse polímero. Esse mecanismo já foi descrito com maiores detalhes em trabalhos anteriores do grupo de pesquisa dos autores [5, $6,12]$. A partir de $200-250{ }^{\circ} \mathrm{C}$ e até $350^{\circ} \mathrm{C}$, o nível de vazão da amostra com fibras vegetais começa a aumentar e atinge valor próximo ao daquela contendo fibras de polipropileno. Para a amostra de referência, o nível de vazão permanece 

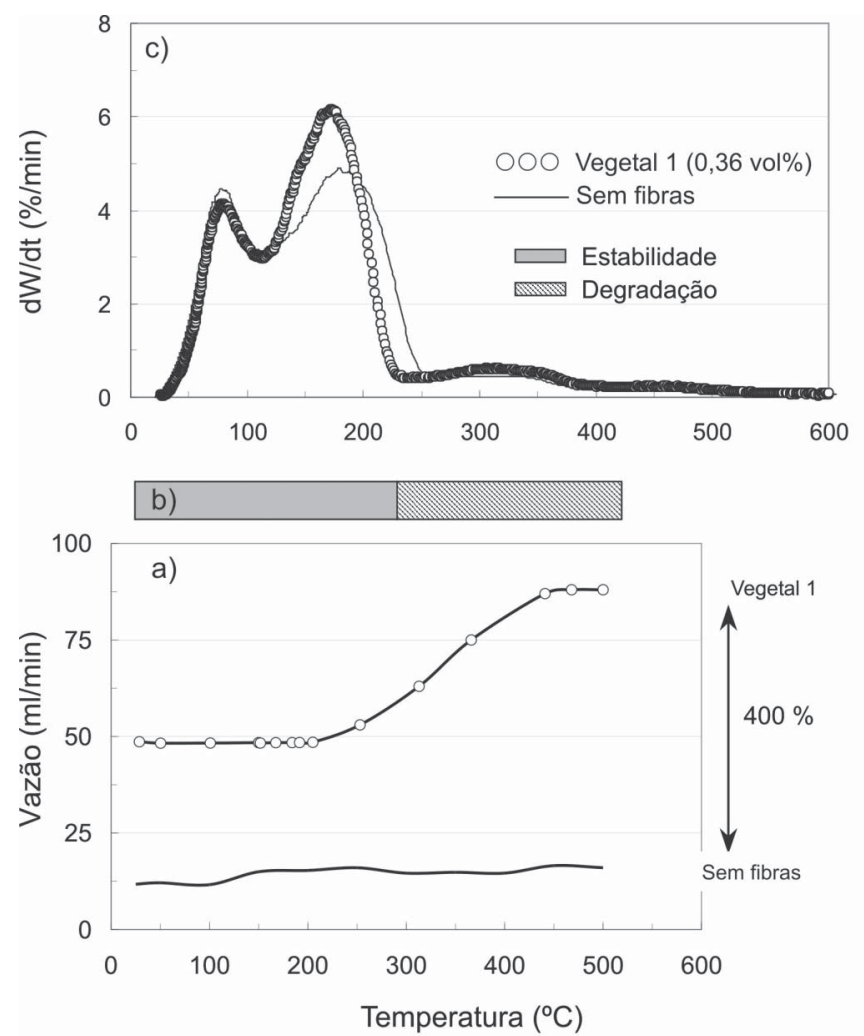

Figura 6: a) Permeametria de ar quente (segundo estágio de aquecimento: $50{ }^{\circ} \mathrm{C}$ a $600{ }^{\circ} \mathrm{C}$ ), b) Caracterização térmica das fibras e c) Comportamento de secagem a $10{ }^{\circ} \mathrm{C} / \mathrm{min}$ para amostras de concretos com fibras vegetal 1 .

[Figure 6: a) Hot air permeametry (second stage: $50{ }^{\circ} \mathrm{C}$ to $600{ }^{\circ} \mathrm{C}$ ), b) Thermal characterization of vegetal 1 fibers and c) Drying behavior at $10^{\circ} \mathrm{C} / \mathrm{min}$ for samples containing vegetal 1 fibers).

similar ao inicial.

Por volta de $120^{\circ} \mathrm{C}$, o comportamento de secagem das amostras com fibras vegetais começa a se distanciar daquele correspondente à amostra com fibras de polipropileno e a de referência (Figs. 5c, 6c e 7c). Os concretos contendo fibras vegetais apresentaram um segundo pico (correspondente à saída de água na forma de vapor pressurizado) [13] mais intenso e em menor temperatura que as outras amostras, indicando que a elevada permeabilidade induzida pela secagem das fibras vegetais faz com que a taxa de saída de água seja $\approx 20 \%$ maior e ocorra em intervalos de tempo e temperatura inferiores. As curvas das amostras sem fibras e com fibras de polipropileno só se diferenciam depois de $\approx 150{ }^{\circ} \mathrm{C}$. Nesse ponto, a fusão do polímero aumenta a permeabilidade do concreto, levando a taxas de secagem $\approx 8 \%$ superiores ao concreto de referência [14].

A relação entre os diversos resultados indica que o aumento de permeabilidade gerado, tanto pelas fibras sintéticas quanto vegetais, leva a uma modificação no comportamento de secagem dos concretos refratários. No entanto, o fato das fibras vegetais possibilitarem que este aumento de permeabilidade ocorra em menores temperaturas (antes da degradação das fibras e próximo à temperatura de ebulição da água), favorece o aumento da taxa de secagem. Além disso, é razoável supor
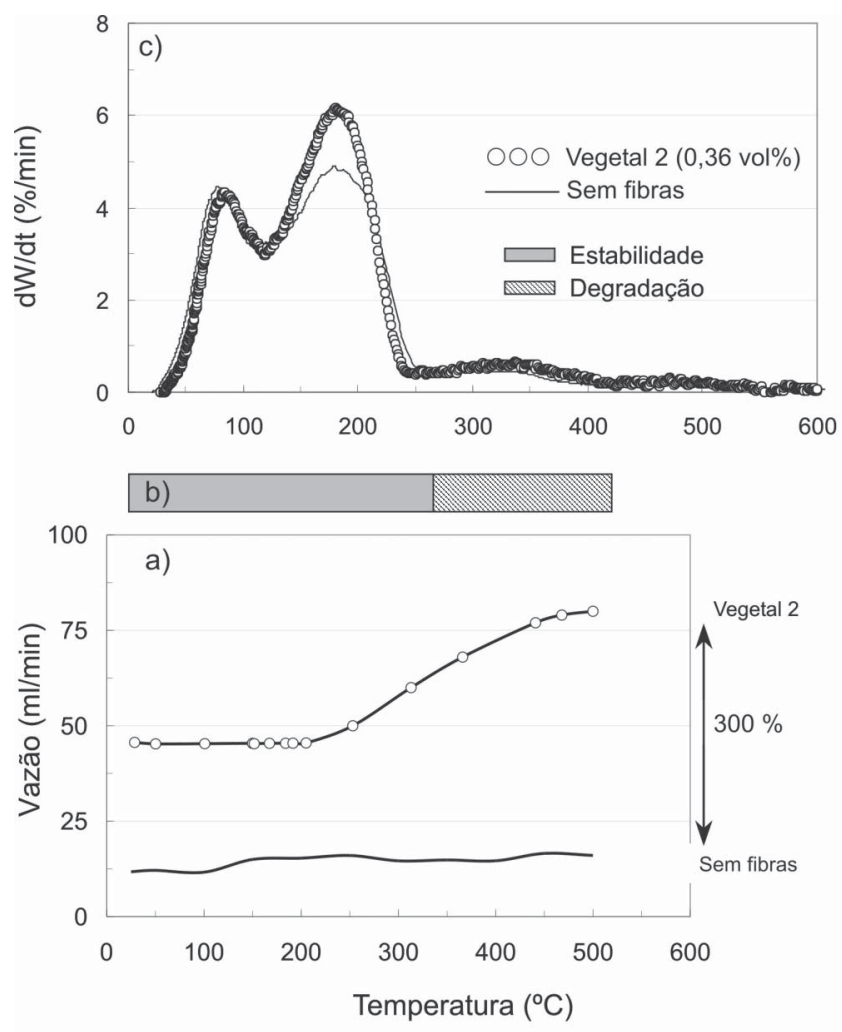

Figura 7: a) Permeametria de ar quente (segundo estágio de aquecimento: $50^{\circ} \mathrm{C}$ a $600{ }^{\circ} \mathrm{C}$ ), b) Caracterização térmica das fibras e c) Comportamento de secagem a $10{ }^{\circ} \mathrm{C} / \mathrm{min}$ para amostras de concretos com fibras vegetal 2.

[Figure 7: a) Hot air permeametry (second stage: $50{ }^{\circ} \mathrm{C}$ to $600{ }^{\circ} \mathrm{C}$ ), b) Thermal characterization of vegetal 2 fibers and c) Drying behavior at $10^{\circ} \mathrm{C} / \mathrm{min}$ for samples containing vegetal 2 fibers.]

que a presença de fibras vegetais também possa reduzir consideravelmente os riscos de explosão durante a secagem.

\section{CONCLUSÕES}

Os resultados apresentados mostraram que tanto fibras de polipropileno como as vegetais podem apresentar um bom desempenho como aditivos de secagem. Ambos os tipos de fibras modificaram o comportamento de secagem dos concretos refratários por meio da geração de aumentos de permeabilidade. Para o concreto com fibras de polipropileno, esse aumento ocorreu após a fusão e degradação das fibras $\left(150-220^{\circ} \mathrm{C}\right)$. Para aquele contendo fibras vegetais, o aumento de permeabilidade se deu em duas etapas: a primeira ocorre em baixas temperaturas (abaixo de $100^{\circ} \mathrm{C}$ ), devido à contração diametral das fibras durante a secagem. A segunda etapa acontece em altas temperaturas, durante a degradação das fibras $\left(217-408^{\circ} \mathrm{C}\right)$. Essa diferença na temperatura de início de aumento de permeabilidade permite que os concretos com fibras vegetais apresentem taxas de secagem superiores e um tempo necessário para secagem menor que aquele sem fibras e/ou com fibras de polipropileno. Considerando, ainda, seu baixo custo e a grande disponibilidade, as fibras vegetais podem se tornar uma interessante alternativa às de 
polipropileno atualmente utilizadas.

\section{AGRADECIMENTOS}

Os autores agradecem a FAPESP, ALCOA e Magnesita S.A. pelo suporte fornecido para a realização deste trabalho; ao CNPq (PIBIC) pela bolsa concedida e a Fitesa S.A. pelas amostras de fibras gentilmente cedidas.

\section{REFERÊNCIAS}

[1] R. E. Moore, J. D. Smith, W. L. Headrick Jr, T. P. Sandler, T.P., Proceedings of the $32^{\text {th }}$ Annual Symposium on Refractories, St. Louis Section of The Am. Ceram. Soc, St. Louis, EUA (1996) 1-6.

[2] P. H. Havranek, Am. Ceram. Soc. Bull. 62, 2 (1983) 234243.

[3] T. R. Kleeb, J. A. Caprio, Advances in Ceramics, 13, ed. by Robert Fisher, The Am. Ceram. Soc. (1985) 149-161.

[4] J. M. Canon, T. P. Sandler, J. D. Smith, R. E. Moore, Proceedings of The Unified International Technical Conference on Refractories - UNITECR' 97, New Orleans, EUA (1997) 583-592.
[5] M. D. M. Innocentini, R. Salomão, C. Ribeiro, F. A. Cardoso, L. R. M. Bittencourt, R. P. Rettore, V. C. Pandolfelli, Am. Ceram. Soc. Bull. 81, 6 (2002) 34-37.

[6] M. D. M. Innocentini, R. Salomão, C. Ribeiro, F. A. Cardoso, L. R. M. Bittencourt, R. P. Rettore, V. C. Pandolfelli, Am. Ceram. Soc. Bull. 81, 7 (2002) 65-68.

[7] F. Khan, S. R. Ahmad, Pol. Degr. Stab. 52 (1996).

[8] R. M. Rowell, H. P. Stout, Handbook Of Fiber Chemistry, M. Lewin, E. M. Pearce, (Editores), Marcel Dekker, Inc., New York (1998).

[9] M. G. Ferri, Plantas Produtoras de Fibras, E.P.U. (1976). [10] A. R. Studart, R. G. Pileggi, J. Gallo, V. C. Pandolfelli, Am. Ceram. Soc. Bull. 80, 11 (2001).

[11] M. D. M. Innocentini, A. R. F. Pardo, V. C. Pandolfelli, J. Am. Ceram. Soc. 85, 6 (2002) 1517-1521.

[12] M. D. M. Innocentini, C. Ribeiro, R. Salomão, L. Bittencourt, V. C. Pandolfelli, J. Am. Ceram. Soc. 85, 8 (2002) 2110-2112.

[13] M. D. M. Innocentini, F. A. Cardoso, M. M. Akyioshi, V. C. Pandolfelli, J. Am. Ceram. Soc. 86, 7 (2003) 1146-1148.

[14] R. Salomão, F. Cardoso, M. D. M. Innocentini, V. C. Pandolfelli, Am. Ceram. Soc. Bull. 82, 4 (2003) 51-56.

(Rec. 20/06/03, Ac. 03/10/03) 